\title{
Discrepancy between mRNA and Protein Expression of Neutrophil Gelatinase-Associated Lipocalin in Bronchial Epithelium Induced by Sulfur Mustard
}

\author{
Majid Ebrahimi, ${ }^{1}$ Mehryar Habibi Roudkenar, ${ }^{2}$ Abbas Ali Imani Fooladi, ${ }^{3}$ \\ Raheleh Halabian, ${ }^{2}$ Mostafa Ghanei, ${ }^{1}$ Hisatake Kondo, ${ }^{4}$ and Mohammad Reza Nourani ${ }^{1}$ \\ ${ }^{1}$ Chemical Injury Research Center (CIRC), Baqiyatallah University of Medical Sciences, Tehran 114359-44711, Iran \\ ${ }^{2}$ Research Center, Iranian Blood Transfusion Organization, Tehran 1157-14665, Iran \\ ${ }^{3}$ Research Center of Molecular Biology, Baqiyatallah University of Medical Sciences, Tehran 114359-44711, Iran \\ ${ }^{4}$ Division of Histology, Department of Rehabilitation, School of Medical Sciences \& Welfare, Tohoku Bunka Gakuen University, \\ Sendai 981-8551, Japan \\ Correspondence should be addressed to Mohammad Reza Nourani, r.nourani@yahoo.com
}

Received 22 October 2009; Accepted 8 March 2010

Academic Editor: Rita Casadio

Copyright ( $\odot 2010$ Majid Ebrahimi et al. This is an open access article distributed under the Creative Commons Attribution License, which permits unrestricted use, distribution, and reproduction in any medium, provided the original work is properly cited.

Sulfur mustard (SM) is a potent vesicant that has been employed as a chemical weapon in various conflicts during the 20th century. More recently, mustard was used in the Iraq conflict against Iranian troops and civilians. At the present time there are more than 40.000 people suffering from pulmonary lesions special bronchiolitis obliterans (BOs) due to mustard gas. SM increases the endogenous production of reactive oxygen species (ROS). Neutrophil Gelatinase-associated Lipocalin 2 (Lcn2, NGAL) is a member of the lipocalin superfamily for which a variety of functions such as cellular protection against oxidative stress have been reported. Ten normal and Twenty SM-induced COPD patient individuals were studied. Assessment of NGAL expressions in healthy and the patients endobrinchial biopsies were performed by semiquantitative RT-PCR, real-time RT-PCR, and Immunohistochemistry analysis. While Normal control samples expressed same level of mRNA NGAL, expression level of mRNA-NGAL was upregulated about 1.4- to 9.8-folds compared to normal samples. No significant immunoreactivity was revealed in both samples. As we are aware this is the first report of induction of NGAL in patients exposed to SM. NGAL may play an important role in cellular protection against oxidative stress toxicity induced by mustard gas in airway wall of patients.

\section{Introduction}

Sulfur mustard (SM) or bis (2-chloroethyl) sulfide, a representative of chemical warfare agents (CWA), is a sturdy alkylating agent with identified mutagenic and supposed carcinogenic characteristics [1]. More recently, SM was used by Iraqi forces to target Iranian army and civilians during the latter years of the Iran-Iraq war lasting through 19841988 [2]. From the public health point of view the delayed toxicity and complication of SM is much more serious than its acute poisoning, as experienced through the Iran-Iraq conflict: About one-third of more than 1000,000 Iranians who were exposed to SM are still suffering from long-term respiratory, ocular, and dermal squeals, among which the respiratory one is the most serious $[3,4]$.

Recently, bronchiolitis obliterans (BO) has been reported as a main respiratory clinical complication in patients exposed to SM [5, 6]. Major symptoms of BO are represented by progressive dyspnea and airflow limitations; moreover, mucostasis and mucosal inflammatory reaction are usually associated with $\mathrm{BO}$ [7]. A number of other factors have been shown to be associated with development of $\mathrm{BO}$ such as transplantations of bone marrow, lung, and heart-lung [8], pulmonary infections [9], drug reaction [10], and toxic inhalation [11]. However, some differences in the symptoms of SM-related BO have been reported to be present from 
TABLE 1: Subject characteristics.

\begin{tabular}{lccccc}
\hline Groups & $N$ & $\begin{array}{c}\text { Sex } \\
(\mathrm{M} / \mathrm{F})\end{array}$ & Age range & Age mean $\pm \mathrm{SD}$ & $P$ \\
\hline Control group & 10 & $9 / 1$ & $39.0-44.0$ & $41.3 \pm 2.5$ & .64 \\
SM-injured group & 20 & $20 / 0$ & $36.0-58.0$ & $43.2 \pm 6.4$ & \\
\hline
\end{tabular}

those of $\mathrm{BO}$ caused by the other factors: no progressive pattern along with fibrosis. $[12,13]$.

Although the exact mechanisms of SM-associated respiratory complications of delayed form are not fully understood at present, it seems to be different from mechanisms responsible for its acute complications. It has been postulated that SM-induced pulmonary complications are a neutrophil and/or lymphocyte disorder [14]. Moreover it has been shown that the pathogenesis of $\mathrm{BO}$ is closely associated with release of some inflammatory mediators from variety of cell types including, epithelial cells, monocytes/macrophages, neutrophils, eosinophils, and dendritic cells $[15,16]$. This condition is linked with increased production of reactive oxygen and nitrogen species (ROS and RNS), resultsing in oxidative stress that eventually plays an important role in pathogenesis of various lung diseases such as asthma and chronic obstructive pulmonary disease (COPD) [17-19].

Lipocalin superfamily is a broad and evolutionary conserved family of tiny extracellular proteins with a small molecular mass and a $\beta$-sheet [20]. Neutrophil gelatinaseassociated lipocalin (NGAL) which is first identified by Kjeldsen is also termed as lipocalin-2 ( $\operatorname{lcn} 2)$ or human neutrophil lipocalin $(\mathrm{HNL})$ is a $25-\mathrm{kDa}$ glycoprotein that was at first purified from granules of neutrophils [21]. Although the exact pathophysilogical roles of NGAL are not currently fully understood, several possible functions have been ascribed to NGAL, such as transportation of iron and fatty acids [22, 23], induction of apoptosis [24], suppression of bacterial growth [25], and modulation of inflammatory responses [26]. In addition upregulation of NGAL expression under oxidative stress condition has recently been demonstrated and it has proposed a new function for NGAL such as a protective factor against free radicals produced by $\mathrm{H}_{2} \mathrm{O}_{2}$, oxidant compounds [27, 28].

In light of similarities between SM-induced pulmonary complications of delayed form and a number of pulmonary disorders whose pathogenesis oxidative stress and free radicals are involved in, based on the assumption that the expression of NGAL should be altered in SM-exposed victims, the present study was designed to evaluate the expression of NGAL at levels of mRNA and protein in airway biopsy samples of SM-exposed patients in comparison with unexposed group.

\section{Materials and Methods}

2.1. Study Design. Twenty patients (Table 1) who had suffered from delayed respiratory complications due to the exposure to SM through the 1988-1995 Iran-Iraq conflict were grouped as the SM-injured one. The SM-exposure was confirmed through documented evidence of chemical exposures by the military health services at the time of contact and beginning of respiratory symptoms instantaneously after the exposure without symptom-free periods. Moreover, all the patients exhibited symptoms of $\mathrm{BO}$ which were confirmed by high-resolution computerized tomography (HRCT) scan data characterized by expiratory air trapping of more than $25 \%$ and mosaic parenchymal attenuation, and biopsy samples taken in previous studies. On the other hand, ten SMunexposed individuals were enrolled as a control group, who were confirmed as normal by chest X-ray films and highresolution computerized tomography (HRCT) scan as well as regular pulmonary function tests. All participants signed an informed written-consent. This survey was conducted in accordance with a protocol approved by Baqiyatallah Medical Sciences University (BMSU) ethics committee. A summary of the two subject characteristics is shown in Table 1.

In this study, patients with other chronic pulmonary diseases (such as asthma), lung cancer, autoimmune diseases (such as rheumatoid arthritis), diabetes mellitus, pneumonia, or acute infective bronchitis were excluded from the examination target. In addition smokers, addicts, elders, organ transplant recipients, or patients with occupational history of toxic fume exposure were also excluded.

2.2. Endobronchial Biopsy Sampling. All participants underwent the bronchoscopic examination via a flexible fiberoptic bronchoscope (Olympus BF1T, Tokyo, Japan). Endobronchial biopsy samples were taken by a bronchoscopic forceps (Olympus, Tokyo, Japan) through the bronchoscope. $2 \%$ lidocaine was used to anesthetize the upper respiratory tract. Before beginning the procedure, $0.75 \mathrm{mg}$ atropine was given to each case intramuscularly. Supplemental oxygen was given during the procedure, and the oxygen saturation was monitored continuously by the pulse oxymeter. Biopsy samples were obtained from segmental and subsegmental carinae of the right or left lower lobe and they were immediately immersed in Tripure Isolation Reagent (Roche applied science, Germany) at $4^{\circ} \mathrm{C}$ and maintained at $-80^{\circ} \mathrm{C}$ till RNA extraction.

2.3. cDNA Synthesis. Total RNAs from biopsy samples were isolated by Tripure Isolation Reagent (Roche Applied Science, Germany) according to the manufacturer's recommendation. The extracted total RNAs were suspended in $20 \mu \mathrm{l}$ RNase-free water and stored at $-80^{\circ} \mathrm{C}$ for subsequent procedures. The quantity and quality of purified RNAs were verified by Nanodrop spectrophotometer (ND-1000, Wilmington, DE) and electrophoresis in 1\% agarose gel (Cinnagene, Tehran, Iran), respectively. The purified total RNAs were used as templates for cDNA synthesis. Reverse transcription was carried out by SuperScript III reverse transcriptase (Invitrogen, Carlsbad, CA) with $500 \mathrm{ng}$ of extracted RNAs, followed by DNaseI (Invitrogen, Carlsbad, CA) treatment and heat inactivation, to eliminate any contamination with chromosomal DNA. 
TABle 2: Sequence and characteristics of PCR Primers.

\begin{tabular}{lllcc}
\hline Gene (Accession ID) & & Primer sequence $\left(5^{\prime}\right.$ to $\left.3^{\prime}\right)$ & Annealing Tm & Product length (bp) \\
\hline \multirow{2}{*}{ Lcn2 (NM_005564) } & Forward & TCACCTCCGTCCTGTTTAGG & $59^{\circ} \mathrm{C}$ & 242 \\
& Reverse & CGAAGTCAGCTCCTTGGTTC & & \multirow{2}{*}{-actin (NM_001101) } \\
& $\begin{array}{l}\text { Forward } \\
\text { Reverse }\end{array}$ & $\begin{array}{l}\text { TTCTACAATGAGCTGCGTGTGG } \\
\text { GTGTTGAAGGTCTCAAACATGAT }\end{array}$ & $59^{\circ} \mathrm{C}$ & 119 \\
\hline
\end{tabular}

2.4. Assessment of NGAL Gene Expression. Semiquantitative PCR of NGAL gene was performed using recombinant Taq DNA polymerase (Cinnagene, Tehran, Iran) in a thermocycler (mastercycler eppendorf, Hamburg, Germany). Specific primers were designed with aid of primer3 (Input 0.4.0) software (http://frodo.wi.mit.edu/) based on sequences placed in the NCBI GenBank database (http:// www.ncbi.nlm.nih.gov/) and inputted to the BLAST database (NCBI GenBank) to ensure that they had complete homology with our interested genes (Table 2). Subsequent to initial denaturation at $94^{\circ} \mathrm{C}$ for 5 minutes, cDNA was subjected to 30 cycles of PCR consisting of denaturation at $94^{\circ} \mathrm{C}$ for 30 seconds, annealing at $59^{\circ} \mathrm{C}$ for 30 seconds, and extension at $72^{\circ} \mathrm{C}$ for 60 seconds followed by a 5 -minute terminal extension cycle at $72^{\circ} \mathrm{C}$. PCR products were separated by electrophoresis on a $2 \%$ agarose gel (Cinnagene, Tehran, Iran), to determine successful amplification.

Quantitative real-time PCR analysis was conducted in a Rotor-Gene RG 3000 (Corbett Research, Sydney, Australia). Amplification was done using SYBR Green Premix (Takara, Shiga, Japan) according to the manufacturer's protocol. PCR condition was as follows: initial denaturation at $94^{\circ} \mathrm{C}$ for 1 minute pursued by 40 amplification cycles consisting of denaturation at $94^{\circ} \mathrm{C}$ for 20 seconds, annealing at $59^{\circ} \mathrm{C}$ temperature for 30 seconds and extension at $72^{\circ} \mathrm{C}$ for 30 seconds. $\beta$-actin expression was used to normalize threshold cycle $(\mathrm{Ct})$ values and gave a control for relative quantitative evaluation of the transcripts abundance.

2.5. Immunohistochemical Staining. For immunohistochemistry, details were already described elsewhere by us [29]. In summary, individual airway wall biopsies were fixed with $4 \%$ buffered paraformaldehyde. The biopsies were extirpated and immersed overnight in a phosphate buffer containing $30 \%$ sucrose. Sections, $20 \mu \mathrm{m}$ in thickness, were cut on a cryostat and incubated with NGAL-antibody at appropriate concentrations for 12 hours at $4^{\circ} \mathrm{C}$. The antibody employed in this study included a rat monoclonal antibody raised against NGAL of human origin (Santa cruz biothechnology, Inc, USA) at a dilution $1: 200$. After incubation with the primary antibody, the sections were incubated with biotinylated antirat secondary antibody (Santa cruz biothechnology, Inc, USA) for immunostaining. The sections for immunostaining were subsequently visualized using $\mathrm{ABC}$ complex (avidinbiotinylated peroxidase complex) system (Vector Laboratory, Burlingame, CA, USA) with DAB as a substrate.

2.6. Statistical Analysis. Numerical data are expressed as mean \pm SD of fold changes of NGAL gene expression in

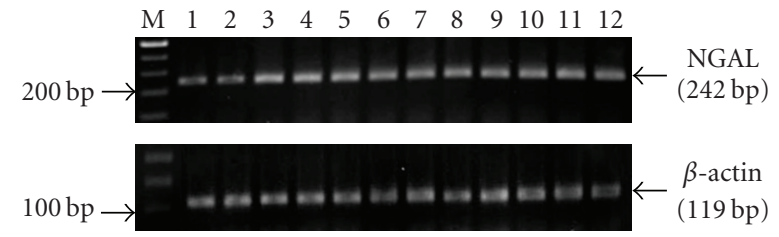

(a)

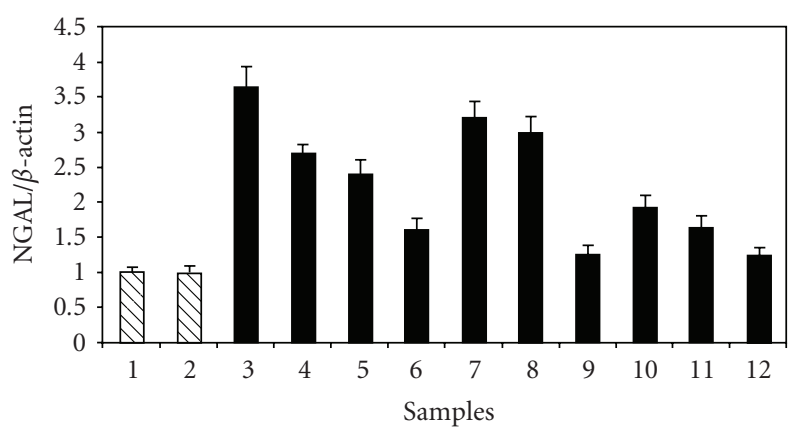

(b)

FIgURE 1: Upregulation of Lcn2 in SM-injured patients. Gene expressions (a) were measured by semiquantitative RT-PCR. Lcn2 was upregulated in SM-injured patients (Lanes 3-12). Only 10 samples have been shown, compared to two normal samples (Lanes 1 and 2). M: 100-bp marker. (b) Ratio of NGAL/beta-actin has also been shown by a histogram.

three independent experiments. Differences between the two groups were compared using student's $t$-test $(P<.05)$

\section{Results}

In the present study 20 airway biopsy specimens from SMinjured patients and 10 samples from unexposed control people were collected (Table 1). Expression was detected in either of the samples.

The expression of NGAL mRNA was studied in the SM-exposed specimens. First, semiquantitative RT-PCR was carried out. Since the control samples expressed the equal level of NGAL, only two of them were used for comparison with the SM-injured patients. As presented in Figure 1 in all SM-poisoned cases (Lanes 3-12) NGAL was upregulated (Lanes 1 and 2).

Then, NGAL expression quantitatively evaluated in the SM-injured patients by real-time RT-PCR. Our result showed that expression of NGAL in mRNA level increased from 1.4- to 9.8-folds compared with the control samples (Table 3). 
TABLE 3: Lcn2 expression fold changes in SM-exposed patients in comparison with control group ( ${ }^{*}$ Statistical significance: $\left.P<.05\right)$.

\begin{tabular}{lcc}
\hline No & $\begin{array}{c}\text { Fold changes of gene expression } \\
\text { (Real-time PCR) }\end{array}$ & $P$ Value \\
\hline 1 & $1.40 \pm 0.28$ & $.045^{*}$ \\
2 & $2.32 \pm 0.23$ & $.015^{*}$ \\
3 & $2.04 \pm 0.41$ & $.016^{*}$ \\
4 & $2.21 \pm 0.51$ & $.01^{*}$ \\
5 & $2.07 \pm 0.69$ & $.04^{*}$ \\
6 & $2.52 \pm 0.34$ & $.03^{*}$ \\
7 & $4.05 \pm 0.60$ & $.007^{*}$ \\
8 & $6.11 \pm 0.87$ & $.005^{*}$ \\
9 & $5.01 \pm 0.53$ & $.004^{*}$ \\
10 & $5.27 \pm 0.81$ & $.001^{*}$ \\
11 & $4.10 \pm 0.57$ & $.007^{*}$ \\
12 & $4.90 \pm 0.84$ & $.005^{*}$ \\
13 & $4.31 \pm 0.43$ & $.004^{*}$ \\
14 & $9.80 \pm 1.05$ & $.001^{*}$ \\
15 & $0.87 \pm 0.95$ & .3 \\
16 & $2.45 \pm 0.26$ & $.01^{*}$ \\
17 & $1.71 \pm 1.13$ & .087 \\
18 & $0.92 \pm 0.45$ & .06 \\
19 & $6.15 \pm 0.98$ & $.001^{*}$ \\
20 & $7.92 \pm 0.75$ & $.001^{*}$ \\
\hline
\end{tabular}

To investigate whether SM induces NGAL expression in protein level immunohistochemistry was performed. A weak expression of NGAL was observed in the bronchial epithelial cells of control group, suggesting basal expression (Figure 2(a)) In contrast, in SM-injured patients, immunoreactiovity for NGAL in the same cells was negative; in particular, the bronchial epithelial cells display immunonegative reactivity for NGAL (Figure 2(b)).

\section{Discussion}

Iran is one of the countries in which SM-injured patients are prevalent, and thousands of Iranians are still suffering from long-term complications of such chemical warfare agents [3]. The latest reports have shown that $\mathrm{BO}$ is the main chronic pulmonary complication among Iranian SMexposed patients which poisoned with this inhalant during Iran-Iraq conflict [13]. Unfortunately very little is identified about the exact molecular mechanisms involved in structural modifications and pathophysilogical symptoms observed in the lung of these patients.

Our results in the present study revealed that the expression of NGAL at mRNA levels was upregulated significantly in airways of SM-exposed patients in comparison with unexposed control group.

To our knowledge, there have been no reports on the expression change of NGAL and its interaction with SMinduced pulmonary complications of delayed form.

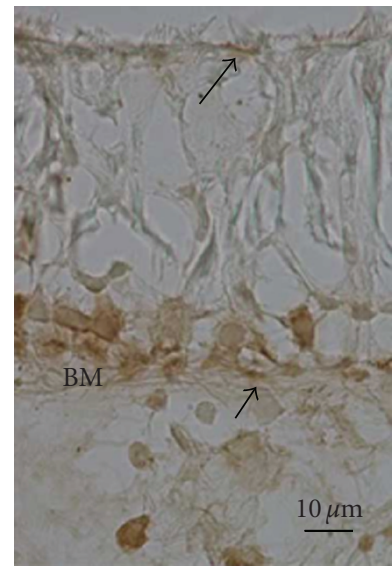

(a)

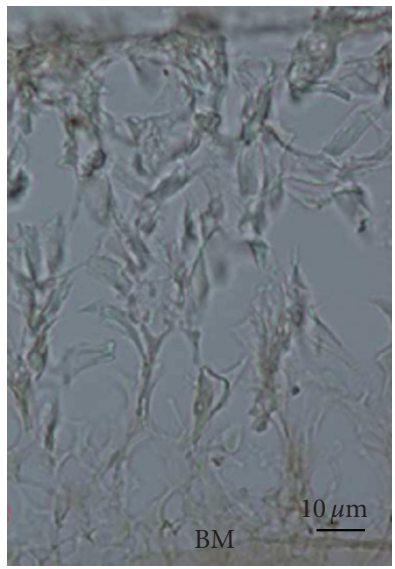

(b)
FIGURE 2: Light micrograph of NGAL-immunoposive cells in the bronchial epithelium. (a) NGAL-immunoreactivity in bronchial epithelial cell of control group. NGAL-immunopositivity weakly demonstrated in substantial number of cells vicinity to basement membrane (BM) (short arrow) and rarely in the luminal border of epithelial cell (long arrow). (b) Immunoreactivity intensity decreased at bronchial epithelial cell of chemical injured patients and no immunoreactions is seen throughout the section. Note that the thickness of epithelial cell layer in experimental group is higher than control group due to chemical injury. BMbasement membrane.

There have recently been studies in which the upregulation of its expression under oxidative stress conditions was revealed and thus a new functional role of NGAL is proposed as a protective factor against free radicals produced by oxidant compounds such as $\mathrm{H}_{2} \mathrm{O}_{2}[27,28]$. NGAL has been suggested to play roles in downregulating the inflammatory response by binding to some cytokines and reducing their biologic activities. NGAL has been reported to stimulate the apoptosis, which may contribute to its anti-inflammatory activity [30]. The overexpression of NGAL has been shown to reduce the adhesion and invasion of cancer cells in vitro and in vivo $[31,32]$.

The recent finding that $\mathrm{SM}$ increases the endogenous production of reactive oxygen species (ROSs) [33] has suggested that ROSs are likely to be involved in the toxicity of this chemical warfare agent-induced toxicity $[34,35]$. The imbalance between oxidant and antioxidant is suggested to be involved in the pathophysiology of SM-induced pulmonary lesions, and thus the antioxidant treatment may be useful in the patients [6]. Several studies have shown the importance of oxidative stress in the pathogenesis of chronic obstructive pulmonary disease (COPD) [36-38], whose signs and symptoms are similar to delayed pulmonary sequels observed in SM-injured patients.

Similar to our findings, Keatings and Barnes [39] reported that the concentration of human neutrophil lipocalin (HNL/NGAL) was elevated in the sputum of patients with asthma or chronic obstructive pulmonary disease (COPD) and could be a better discriminating indicator in comparison with myeloperoxidase (MPO). In another 
study, Eichler et al. [40] showed that the serum levels of HNL/NGAL in patients with cystic fibrosis were noticeably increased and strongly postulated that the determination of serum concentration of this protein may be another useful diagnostic tool for monitoring of neutrophilic inflammation in CF patients.

In addition, it has been demonstrated that the level of HNL/NGAL was significantly increased in bronchoalveolar lavage fluid (BAL) from subjects with subclinical emphysema confirmed by computerized tomography compared with relatively heavy smoker-persons without emphysema [41]. In this case it is accepted that pulmonary emphysema represents a result of proteinase-antiproteinase imbalance in the lungs, which can be induced by cigarette smoke [42]. That leads to the release of large amounts of toxic oxygen radicals and a variety of granule proteins from neutrophils, among which NGAL is included as the most important one [43]. But, our histological findings did not display emphysema in the lung of SM-exposed patients, indicating that SMexposure did not activate the proteinase-antiproteinase imbalance.

In contrast to the mRNA level, the present study showed the localization of NGAL in bronchial epithelial cells in SMexposed and unexposed patients; no significant expression level of NGAL protein was detected in both groups.

The unchanged expression of NGAL protein after long-term SM induction was however not parallel by increased mRNA expression. Exhibited paradoxical discrepancy between the mRNA levels and protein levels of NGAL is most likely due to translational efficiency or posttranslational regulation. Therefore lack of NGAL protein is one important reason of remaining and progressive lesion. NGAL is a protective factor against free radicals, probably able to decrease the toxic effects of free radicals and improve clinical conditions.

We have previously observed that a 4-month administration of $\mathrm{N}$-acetylcysteine in patients exposed to SM could significantly improve FEV1/FVC over placebo $[14,44]$.

It seems that the upregulation of NGAL in these patients may play an advantageous role in decreasing oxidative stresses induced by ROS as a cytoprotective agent to reduce the lung injury and improve patients' symptoms, but optimal cure has not been taken place.

In conclusion our study demonstrated that expression of NGAL in mRNA levels in sulfur mustard injured veterans significantly increased compared with control group. The upregulation could act as a cytoprotective factor to ameliorate sulfur mustard-induced toxicity. But following the increasing folds in mRNA the NGAL protein expression due to unknown reason does not increased and this is the main reason for unconvalesce in this disease. However, further and complementary studies are required to clarify mechanisms underlying SM exerts cytotoxicity.

\section{References}

[1] T. C. Marrs, R. L. Maynard, and F. R. Sidell, "Mustard gas," in Chamical Warfare Agents, Toxicology and Treatment, chapter 6, pp. 139-173, Jahn Wiley \& Sons, London, UK, 1996.
[2] United Nations Security Council, Report of the Mission Dispatched by the Secretary General to Investigate Allegations of the Use of Chemical Weapons in the Conflict between the Islamic Republic of Iran and Iraq. S/19823, United Nations, New York, NY, USA, 1988.

[3] S. Khateri, M. Ghanei, S. Keshavarz, M. Soroush, and D. Haines, "Incidence of lung, eye, and skin lesions as late complications in 34000 Iranians with wartime exposure to mustard agent," Journal of Occupational and Environmental Medicine, vol. 45, no. 11, pp. 1136-1143, 2003.

[4] M. Ghanei, J. Aslani, S. Khateri, and K. Hamadanizadeh, "Public health status of the civil population of Sardasht 15 years following large-scale war time exposure to sulfur mustard," Journal of Burns and Surgical Wound Care, vol. 2, no. 1, p. 7, 2003.

[5] J. W. W. Thomason, T. W. Rice, and A. P. Milstone, "Bronchiolitis obliterans in a survivor of a chemical weapons attack," Journal of the American Medical Association, vol. 290, no. 5, pp. 598-599, 2003.

[6] M. Ghanei, M. Mokhtari, M. M. Mohammad, and J. Aslani, "Bronchiolitis obliterans following exposure to sulfur mustard: chest high resolution computed tomography," European Journal of Radiology, vol. 52, no. 2, pp. 164-169, 2004.

[7] P. Laohaburanakit, A. Chan, and R. P. Allen, "Bronchiolitis obliterans," Clinical Reviews in Allergy and Immunology, vol. 25, no. 3, pp. 259-274, 2003.

[8] M. Estenne, J. R. Maurer, A. Boehler, et al., "Bronchiolitis obliterans syndrome 2001: an update of the diagnostic criteria," Journal of Heart and Lung Transplantation, vol. 21, no. 3, pp. 297-310, 2002.

[9] A. B. Chang, J. P. Masel, and B. Masters, "Post-infectious bronchiolitis obliterans: clinical, radiological and pulmonary function sequelae," Pediatric Radiology, vol. 28, no. 1, pp. 2329, 1998.

[10] A. Boehler, P. Vogt, R. Speich, W. Weder, and E. W. Russi, "Bronchiolitis obliterans in a patient with localized scleroderma treated with D-penicillamine," European Respiratory Journal, vol. 9, no. 6, pp. 1317-1319, 1996.

[11] K. D. Markopoulou, C. D. Cool, T. L. Elliot, et al., "Obliterative bronchiolitis: varying presentations and clinicopathological correlation," European Respiratory Journal, vol. 19, no. 1, pp. 20-30, 2002.

[12] M. Ghanei, M. Ghayumi, N. Ahakzani, et al., "Noninvasive diagnosis of bronchiolitis obliterans due to sulfur mustard exposure: could high-resolution computed tomography give us a clue?" Radiologia Medica, vol. 115, pp. 413-420, 2010.

[13] M. Ghanei, H. D. Tazelaar, M. Chilosi, et al., "An International collaborative pathologic study of surgical lung biopsies from mustard gas-exposed patients," Respiratory Medicine, vol. 102, no. 6, pp. 825-830, 2008.

[14] M. Ghanei, M. Shohrati, M. Jafari, S. Ghaderi, F. Alaeddini, and J. Aslani, "N-acetylcysteine improves the clinical conditions of mustard gas-exposed patients with normal pulmonary function test," Basic and Clinical Pharmacology \& Toxicology, vol. 103, no. 5, pp. 428-432, 2008.

[15] G. B. Toews, "Impact of bacterial infections on airway diseases," European Respiratory Review, vol. 14, no. 95, pp. 6268,2005

[16] S. L. Johnston, "Impact of viruses on airway diseases," European Respiratory Review, vol. 14, no. 95, pp. 57-61, 2005.

[17] L. S. Greene, "Asthma, oxidant stress, and diet," Nutrition, vol. 15, no. 11-12, pp. 899-907, 1999.

[18] I. Rahman and I. M. Adcock, "Oxidative stress and redox regulation of lung inflammation in COPD," European Respiratory Journal, vol. 28, no. 1, pp. 219-242, 2006. 
[19] J. Madill, E. Aghdassi, B. Arendt, et al., "Lung transplantation: does oxidative stress contribute to the development of bronchiolitis obliterans syndrome?" Transplantation Reviews, vol. 23, no. 2, pp. 103-110, 2009.

[20] D. R. Flower, A. C. T. North, and C. E. Sansom, "The lipocalin protein family: structural and sequence overview," Biochimica et Biophysica Acta, vol. 1482, no. 1-2, pp. 9-24, 2000.

[21] L. Kjeldsen, A. H. Johnsen, H. Sengelov, and N. Borregaard, "Isolation and primary structure of NGAL, a novel protein associated with human neutrophil gelatinase," Journal of Biological Chemistry, vol. 268, no. 14, pp. 10425-10432, 1993.

[22] S. Triebel, J. Blaser, H. Reinke, and H. Tschesche, "A 25 kDa $\alpha 2$-microglobulin-related protein is a component of the 125 kDa form of human gelatinase," FEBS Letters, vol. 314, no. 3, pp. 386-388, 1992.

[23] S.-T. Chu, H.-J. Lin, H.-L. Huang, and Y.-H. Chen, "The hydrophobic pocket of $24 \mathrm{p} 3$ protein from mouse uterine luminal fluid: fatty acid and retinol binding activity and predicted structural similarity to lipocalins," Journal of Peptide Research, vol. 52, no. 5, pp. 390-397, 1998.

[24] L. R. Devireddy, J. G. Teodoro, F. A. Richard, and M. R. Green, "Induction of apoptosis by a secreted lipocalin that is transcriptionally regulated by IL-3 deprivation," Science, vol. 293, no. 5531, pp. 829-834, 2001.

[25] D. H. Goetz, M. A. Holmes, N. Borregaard, M. E. Bluhm, K. N. Raymond, and R. K. Strong, "The neutrophil lipocalin NGAL is a bacteriostatic agent that interferes with siderophoremediated iron acquisition," Molecular Cell, vol. 10, no. 5, pp. 1033-1043, 2002.

[26] B. S. Nielsen, N. Borregaard, J. R. Bundgaard, S. Timshel, M. Sehested, and L. Kjeldsen, "Induction of NGAL synthesis in epithelial cells of human colorectal neoplasia and inflammatory bowel diseases," Gut, vol. 38, no. 3, pp. 414-420, 1996.

[27] M. H. Roudkenar, Y. Kuwahara, T. Baba, et al., "Oxidative stress induced lipocalin 2 gene expression: addressing its expression under the harmful conditions," Journal of Radiation Research, vol. 48, no. 1, pp. 39-44, 2007.

[28] M. H. Roudkenar, R. Halabian, Z. Ghasemipour, et al., "Neutrophil gelatinase-associated lipocalin acts as a protective factor against $\mathrm{H}_{2} \mathrm{O}_{2}$ toxicity," Archives of Medical Research, vol. 39, no. 6, pp. 560-566, 2008.

[29] M. R. Nourani, Y. Owada, N. Kitanaka, et al., "Localization of epidermal-type fatty acid binding protein in macrophages in advanced atretic follicles of adult mice," Journal of Molecular Histology, vol. 36, no. 6-7, pp. 391-400, 2005.

[30] J. Ryon, L. Bendickson, and M. Nilsen-Hamilton, "High expression in involuting reproductive tissues of uterocalin/24p3, a lipocalin and acute phase protein," Biochemical Journal, vol. 367, no. 1, pp. 271-277, 2002.

[31] Z. Tong, X. Wu, D. Ovcharenko, J. Zhu, C.-S. Chen, and J. P. Kehrer, "Neutrophil gelatinase-associated lipocalin as a survival factor," Biochemical Journal, vol. 391, no. 2, pp. 441448, 2005.

[32] H.-J. Lee, E.-K. Lee, K.-J. Lee, S.-W. Hong, Y. Yoon, and J.-S. Kim, "Ectopic expression of neutrophil gelatinase-associated lipocalin suppresses the invasion and liver metastasis of colon cancer cells," International Journal of Cancer, vol. 118, no. 10, pp. 2490-2497, 2006.

[33] S. Han, L. A. Espinoza, H. Liao, A. H. Boulares, and M. E. Smulson, "Protection by antioxidants against toxicity and apoptosis induced by the sulphur mustard analog 2chloroethylethyl sulphide (CEES) in Jurkat T cells and normal human lymphocytes," British Journal of Pharmacology, vol. 141, no. 5, pp. 795-802, 2004.
[34] A. Korkmaz, H. Yaren, T. Topal, and S. Oter, "Molecular targets against mustard toxicity: implication of cell surface receptors, peroxynitrite production, and PARP activation," Archives of Toxicology, vol. 80, no. 10, pp. 662-670, 2006.

[35] M. R. Naghii, "Sulfur mustard intoxication, oxidative stress, and antioxidants," Military Medicine, vol. 167, no. 7, pp. 573$575,2002$.

[36] R. C. J. Langen, S. H. Korn, and E. F. M. Wouters, "ROS in the local and systemic pathogenesis of COPD," Free Radical Biology and Medicine, vol. 35, no. 3, pp. 226-235, 2003.

[37] I. Rahman and W. MacNee, "Oxidant/antioxidant imbalance in smokers and chronic obstructive pulmonary disease," Thorax, vol. 51, no. 4, pp. 348-350, 1996.

[38] K. Husain, S. N. Dube, K. Sugendran, R. Singh, S. Das Gupta, and S. M. Somani, "Effect of topically applied sulphur mustard on antioxidant enzymes in blood cells and body tissues of rats," Journal of Applied Toxicology, vol. 16, no. 3, pp. 245-248, 1996.

[39] V. M. Keatings and P. J. Barnes, "Granulocyte activation markers in induced sputum: comparison between chronic obstructive pulmonary disease, asthma, and normal subjects," American Journal of Respiratory and Critical Care Medicine, vol. 155, no. 2, pp. 449-453, 1997.

[40] I. Eichler, M. Nilsson, R. Rath, I. Enander, P. Venge, and D. Y. Koller, "Human neutrophil lipocalin, a highly specific marker for acute exacerbation in cystic fibrosis," European Respiratory Journal, vol. 14, no. 5, pp. 1145-1149, 1999.

[41] T. Betsuyaku, M. Nishimura, K. Takeyabu, et al., "Neutrophil granule proteins in bronchoalveolar lavage fluid from subjects with subclinical emphysema," American Journal of Respiratory and Critical Care Medicine, vol. 159, no. 6, pp. 1985-1991, 1999.

[42] R. M. Senior and S. D. Shapiro, "Chronic obstructive pulmonary disease: epidemiology, pathophysiology, and pathogenesis," in Fishman's Pulmonary Diseases and Disorders, pp. 659-681, McGraw-Hill, New York, NY, USA, 3rd edition, 1997.

[43] N. Borregaard and J. B. Cowland, "Granules of the human neutrophilic polymorphonuclear leukocyte," Blood, vol. 89, no. 10, pp. 3503-3521, 1997.

[44] M. Shohrati, J. Aslani, M. Eshraghi, F. Alaedini, and M. Ghanei, "Therapeutics effect of $\mathrm{N}$-acetyl cysteine on mustard gas exposed patients: evaluating clinical aspect in patients with impaired pulmonary function test," Respiratory Medicine, vol. 102, no. 3, pp. 443-448, 2008. 


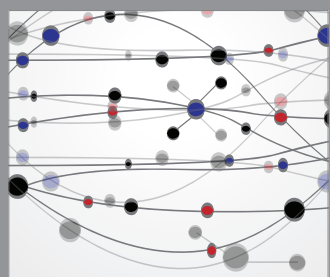

The Scientific World Journal
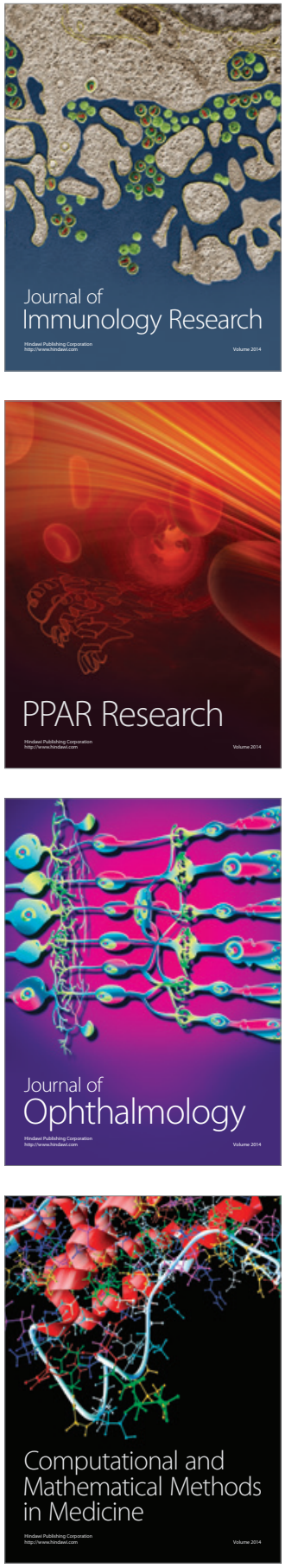

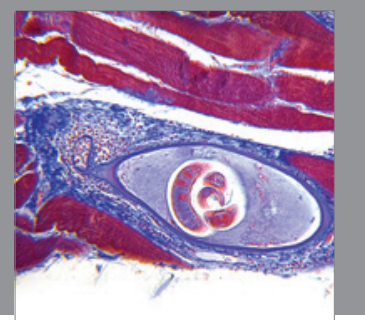

Gastroenterology

Research and Practice
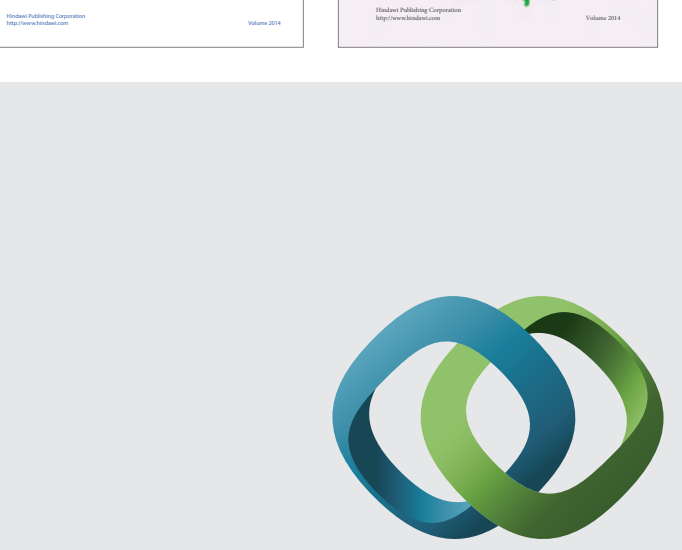

\section{Hindawi}

Submit your manuscripts at

http://www.hindawi.com
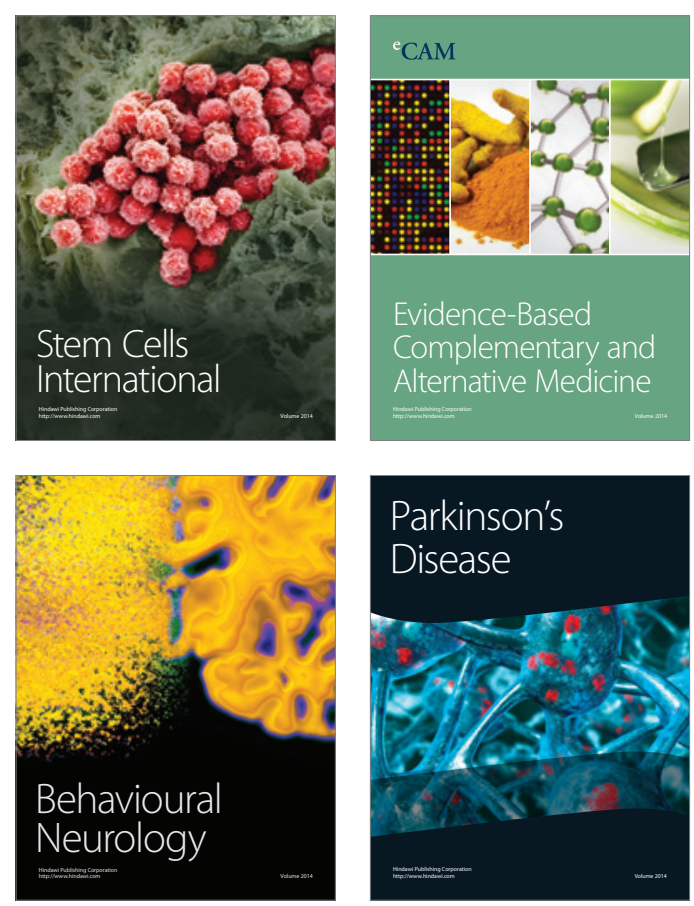

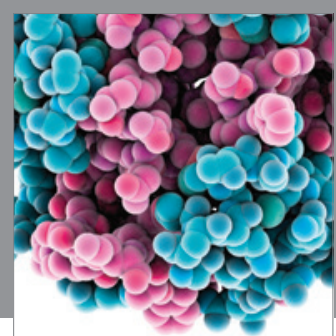

Journal of
Diabetes Research

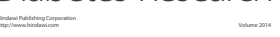

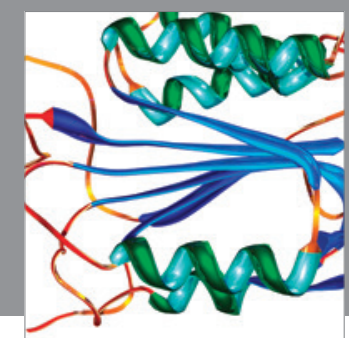

Disease Markers
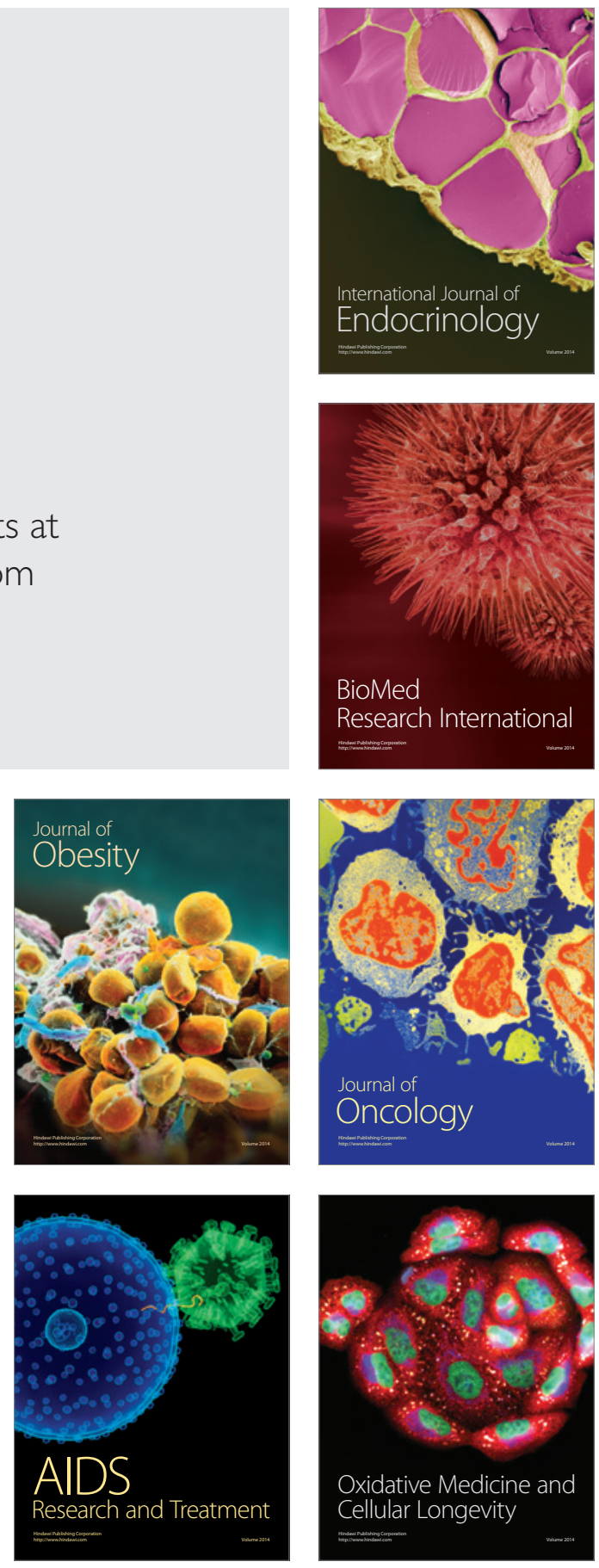